\title{
Applying Cognitive Linguistics to Enhance the Semantics of English at: An Experimental Study (Baghdad University)
}

\author{
Raghad Fahmi Aajami ${ }^{1}$ \\ ${ }^{1}$ Department of English, College of Education for Women, University of Baghdad, Baghdad, Iraq \\ Correspondence: Raghad Fahmi Aajami, Department of English, College of Education for Women, University of \\ Baghdad, Baghdad, Iraq. E-mail: raghad.goldenswan@gmail.com
}

Received: July 2, 2018 Accepted: August 10, 2018 Online Published: August 30, 2018

doi:10.5539/ijel.v8n6p185 URL: https://doi.org/10.5539/ijel.v8n6p185

\begin{abstract}
The current study is quantitative by nature; it cognitively studies the polysemous network of the English preposition at and its various meanings. The results of the pre-test conducted by the researcher have tentatively revealed that Iraqi second language (L2) learners fall in the perplexity because of the multi-usages of this preposition. This incomprehensive view of the preposition at motivates the researcher to analyze this preposition semantically according to insights from cognitive linguistics (CL) that was developed by Evans and Tyler (2003). Accordingly, sixty-eight second year university students participated in this experimental study. The pre-test and post-test data were analyzed using SPSS. Results have shown the following: First, a progress of more than $(0.05 \leq)$ has been detected as far as students' understanding of the multiple usages of the preposition at. Second, the results of the questionnaire have shown a prominent positive change in the students' attitude toward CL approach. Third, the main source of difficulty regarding the diversity in the semantics of the preposition at has been displayed. Fourth, CL as an approach has proven its effectiveness in accurately comprehending of the semantics of the English preposition at.
\end{abstract}

Keywords: cognitive linguistic, semantic, English prepositions

\section{Introduction}

In Iraq, English is considered as a second language. Linguists as well as English teachers have long noticed that generally the acquisition of prepositions is a major challenge for L2 learners (Celce-Murcia \& Larsen-Freeman, 1999). Besides, Arab learners sometimes use expressions without prepositions. For instance, they say "to discuss" not "to discuss about", or "to marry" not "to marry with" (Saed \& Yassin, 2017). For example, recognizing the difference between the prepositions by and with is far unclear. On one hand, the sentence: "The text is linked by a code", is a near paraphrase of: "The text is linked with a code". On the other hand, the sentence: "the text is written by Mary" is semantically interpreted quite differently from: "the text is written with Mary".

CL approach offers a full analysis of English prepositions and other languages, too. It elicits the meaning of a preposition as schematizing the spatial configuration between two entities, an abstract notion, and a functional element (Tyler \& Evans, 2003). These CL insights are used in analyzing the English preposition at. Thus, this study is to test the effectiveness of CL approach in accurately and systematically comprehending the English preposition at.

\subsection{Objectives of the Study}

The study aims at examining the extent to which $C L$ as an approach helps increase the participants' ability to elicit the semantics of the English preposition at in their speech contexts.

\subsection{Limitations of the Study}

The study was limited to second-year students in the Department of English /College of Education for Women/ University of Baghdad/ Iraq. It was conducted during the academic year 2017/2018. Sixty-eight participants were randomly selected by putting their names in a basket, shaking the basket and then randomly selecting names.

\section{An Overview of Cognitive Linguistics as an Approach}

This section is primarily devoted to concentrate on CL approach and its practical implementations in obtaining the semantics of English prepositions for L2 learners. George Lakoff, Ron Langacker, and Len Talmy are considered 
the fathers of $\mathrm{CL}$ approach constructed in the early eighties of the $20^{\text {th }} \mathrm{C}$. It deals with the language as a tool of organizing, processing, and conveying information (Geeraerts \& Cuyckens, 2010).

CL approach addresses language issues to be understood according to the individual and social conditions (American Association for Applied linguistics, 2018). In a parallel line to applied linguistics, CL approach focuses on studying language, mind, and sociocultural experience. It is known by its commitment to the continuous correlation of meaning and form in the study of language. CL approach adopts the view that language does not adopt a modular view of mind as much as it reflects general aspects of cognition. It is mainly concentrated on two general areas of analysis: the study of language organization (cognitive grammar) and language as a means of studying aspects of conceptual structure (cognitive semantics) (Evans, 2012).

English prepositions are difficult to be understood since they have multi-meanings or are polysemous. They are the most repetitive words in English, and have a complex set of uses. Therefore, L2 learners face the challenge of comprehending the English prepositions (Celce-Murica \& Larsen-freeman, 1999). Thus, CL approach is used to address this issue out of analyzing the English prepositions and their semantic networks in terms of spatial sense, spatial relations, and figurative sense (Mueller, 2016).

English prepositions construct spatial relations among a land mark and an agent. The multiple meanings associated with English prepositions can be represented as being systematically related within a motivated semantic network (Tyler et al., 2011). The central notion of a spatial scene creates conceptualized relations between two entities in a spatial experience and interaction. For example "the glass of water is on the table", the spatial scene in this example means that there is a contact between the glass and the table. This motivates another scene which is described as "the water is in the glass". These relations are important because without the table, the glass will fall and be broken, and without the glass, the water will spill. The spatial scene involves a support relationship between "the table \& the glass" and "the glass \& the water" (Tyler et al., 2011). The human interaction response to the scene of "the glass of water is on the table" differs due to the viewer's main concentration. One will concentrate on the relation between the table and glass while another on the relation between the glass and the water inside it. Thus, one can get the result that there are no identical vantage points. The way a viewer views the physical vantage point of a spatial scene will determine the way that he will interpret it according to his conceptualization (Evans \& Tyler, 2003).

The central scene extends different spatial relations in a systematic way. Prepositions that describe a contact develop rotated senses (Boers, 1996). For instance, "the glass is on the table" $\rightarrow$ "the jar is on the table"; this is called the spatial relations. Figurative sense is also developed from a spatial scene. Beside the fact that "the glass is on the table" represents a spatial configuration of entities, it further connotes the metaphorical sense that the first entity (the glass) is up and the second entity (the table) is down (Boers \& Demecheleer, 1998).

There are hard works directed to analyze the semantics of English prepositions in terms of CL insights. Rice (1992) finds that the prepositions at, on, and in have spatial and locative functions that help in configuring entities. These prepositions also have multiple-configured grounds and temporal functions. Used temporally, at, on, and in serve to locate an event relative to a brief point, short period, or vast expanse of time. Rice asserts that these prepositions have a deictic function and predicate meaning which are greatly dependent on the speaker's expectations.

When analyzing the polysemous nature of the preposition at, Fernando (1998) explains the way it is understood by natives and researchers. For native speakers, at is considered a point of introducing a complement conceptualization. For researchers, like Hawkins (1984), the conceptual meaning of at has a general locative sense. Cienki (1989), on the other hand, says at has a determined function in the interactions of humans. The dynamic uses of at describe motion and implicate a sense of spatial configuration (Fernando, 1998).

The two main notions, location and the motion, are the central sources of meaning for most of the frequent English prepositions. These central senses are considered the starting points of meanings that extend across other domains by ways of semantic change mechanisms, such as metaphor, frame-of-focus variation, and subjectification. Metaphor which is typically defined as a conceptual mechanism that helps understand and experience a thing in terms of another as in the analysis of Figures 3 and 4. Frame-of-focus variation means that the meaning differs according to the context, for example "I asked out of curiosity" out of means with; in contrast, out of means without in the example "we are out of money". As for subjectification, it involves projecting the speakers' attitude or judgment. When the speaker views two entities, s/he evaluates the more beneficial one, for instance, "the players are at the stadium" (Rhee, 2004).

The cognitive semantic analysis shows that the English preposition at has different matrix domains and sub-domains of meanings in specific categorizations. The matrix domains are time, place, value, direction, condition, and distance. These domains create sub-domains of meaning as duration, state, specific place, unit of 
measurement, outward movement, reaction, reference and others. Such a result has been arrived at when analyzing phrasal verbs, expressions, and normal sentences that involve the preposition at (Al-Bahrani \& Al-Robuye, 2016).

Tyler and Evans (2003) find that the central meaning of at creates a spatial scene between two close objects as in the "the ball is at the corner" Throughout their semantic analysis, Tyler et al. (2011) focus on two senses of the preposition at, the functional sense and the intensity sense. The functional sense appears when the Focus element is a human. If there is a person acting on an inanimate object, then this person is acting for a particular reason. There is co-location for the human and the inanimate object. The focus element, the human, can interact with ground element. As in the example, "Marry is at the drums". The prototypical configuration involves a functional relationship between Marry and the drums. The intensity sense is emerged from the hard interaction between humans as focus elements and inanimate objects, for example "the players are fighting at the basket". The players are busy in attacking and defending the basket to achieve their goals (Tyler et al., 2011).

Tyler and Evans (2004) assert that prepositions are best modelled using CL approach as such an approach spatially diagrams the configuration between a trajector and a land mark, encoding abstract notions, as in: "the policeman shouted at the driver". In this example, the preposition at conveys abstract impression through the verb "shouted". Accordingly, CL has proven to be more accurate and systematic than traditional accounts.

Brala (2008) notices that there are seven semantic analyses of the English preposition at; these include the following: Cooper (1968), Leech (1969), Bennett (1975), Quirk (1985), Herskovits (1986), and Lindstromberg (1997), Tyler and Evans (2003). All these analyses concentrate on the relation between a Figure and a ground. She also finds that there are coincidence of $\mathbf{F}$ and $\mathbf{G}$ in the treatment of at. For example, "Trevor is at the sofa" is an example which speaks loud and clear in favour of coincidence, the dominant semantic trait of at. Coincidence occurs when $\mathbf{G}$ controls the location of $\mathbf{F}$.

Winter \& Christian (2012) find that the meaning of at can be more appropriately formalized by starting from the concept of a contrast set of locations. There is a set of contrasting locations in mind, the meaning of at a location A is limited to locations which are close to A or to any other alternative location to A. The contrast set of locations forms part of the context of the conversation. Place are not characterized by boundaries. Places are rather characterized by prototypes or centers, or are even conceived of as dimensionless entities in information space, for example, "the train is at the station".

Vasardani et al. (2017) prove that at has a spatial locational relation in locative expressions. They also suggest that geographic information science can model the range of uses of preposition at; for instance, "The airport is at the west side of the city". They conclude that at is used when the focus of attention is not on encoding more specific spatial relations between location and reference object but rather on the specification of the reference object as a relevant location; for example, "they are at Canada".

Words, expressions, and constructions have different meanings that are contextually highlighted. Context helps participants to acquire the semantics of these various meanings. The steps of comprehension identify the difference of language usage between a native speaker and a L2 learner (Mandreoli et al., 2005). Thus, the analysis in this study follows Tyler and Evans' model (2003).

All the above mentioned studies verify the polysemous nature of English prepositions, and prove the suitability of $\mathrm{CL}$ approach in comprehending the semantics of English prepositions.

\section{Semantic Analysis of the Preposition " $a$ "}

This section shows the semantic analysis of the preposition at as developed by (Tyler \& Evans, 2003). Cognitive semantic analysis can help overcome the perplexity encountered due to the polysemous nature of the preposition at and get accurate comprehension of its usages and expressions.

Spatial sense can be viewed physically depending on the vantage point of the viewer. As long as this physical view depends on the viewer; therefore, there is no two identical vantage points (Tyler \& Evans, 2004). The first central spatial sense of at can be represented in "the student is at school". School is a land mark, and it is a place. At refers to a specific place which is a school. It defines the place of the student. The trajector "the student" is inside the land mark "the school". This scene can be represented in the following diagram as set by the researcher of the present work. 


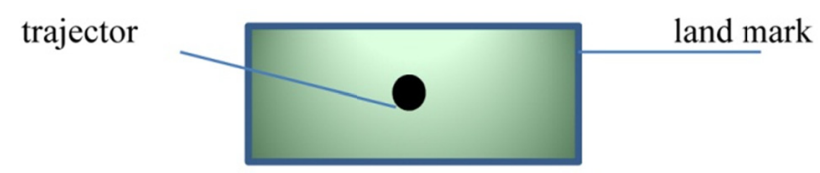

Figure 1. The student is at school

Source: This figure is set by the researcher.

Figure 1 is an example of the spatial relations as in "the student is looking at the teacher". In this sentence, at refers to another entity, "the teacher", and it has a different meaning. Here, there are two entities: one is stable while the other is movable. There is action and target with a non-physical object. This is because the student uses his vision to watch the teacher. In the example, "Tom threw the ball at Hani", there is a spatial sense with a physical object. This further develops a figurative sense that these guys are playing and collaborating to achieve a goal. There is also a sense of motion; these senses are possibly to be highlighted through CL approach, which activates the different and subjective conceptualizations of meaning (Tyler \& Evans, 2003). Figure 1 also indicates the relation between time and place; which can also exist metaphorically within language (Casanto \& Boroditsky, 2008)

Another central sense of at can be represented in "the moon is more beautiful at night"; here, there is a spatial sense and a formalization of a mental image that is defined by time. At defines the best time to see the moon; it also conveys a vertical-horizontal axis depending on the position of the moon. It clearly shows that the physical vantage points do not offer the same view. At shows duration of time; it can be represented in the following diagram. This diagram is set by the researcher.

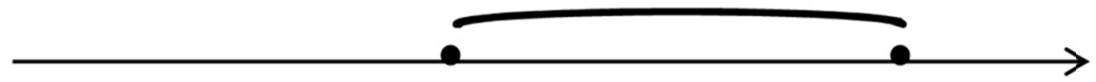

Figure 2. The moon is more beautiful at night

Source: This figure is set by the researcher.

Night is started and ended at specific points. Metaphorically, there is a superlative notion to see the moon at night than other times.

The abstract notion of the preposition at can be represented in the following examples: "Maya is good at English", "Rony is good at shooting", "the mother is angry at her son". These examples show degree, condition, skill, value, scale, stand, direction. That is, angry at her son reflects the sense of reaction as a sub-domain of the matrix domain of condition whereas good at shooting reflects the sense of average, degree, or level as a sub-domain of the matrix domain of condition (Al-Bahrani \& Al-Robuye, 2016).

The back and forth sense of at can be clarified as in "the boss and workers waved at each other". The motion in this example is reciprocal between two entities. The first sends and the second receives, and the second resends to the first. There is a spatial sense which imposes spatial relations between the entities that demonstrate the metaphorical sense as a higher status act and lower status react. Physically, this example shows to the lateral viewer a horizontal axis between two entities. There is also an abstract sense if one highlights the ranks of the two entities "the boss has a higher rank than workers". The following diagrams sets by the researcher show these relations:

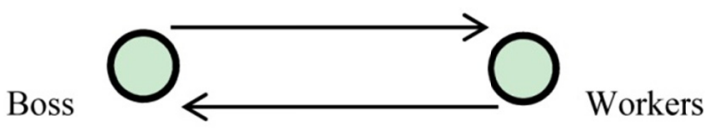

Figure 3. Physical status

Source: This figure is set by the researcher. 


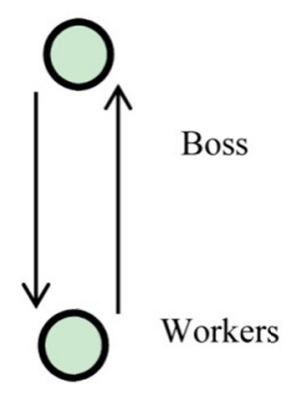

Figure 4. Abstract ranks

Source: This figure is set by the researcher.

\section{The Experiment}

The experiment of this study aims at representing the preposition at in the light of CL insights. To achieve this aim, the researcher conducted an experiment that involved the following:

1) using pictures that help illustrating the spatial sense of the preposition at;

2) asking the participants to conceptualize the spatial sense from the displayed pictures;

3) answering a test to measure the participants' right choice of prepositions that suits and completes the meaning of a sentence;

4) Results of the pre-test and post-test were quantitatively analyzed using paired sample statistics, the SPSS.

\subsection{Participants and Procedures}

The participants were sixty-eight second year university students. Those participants had no prior idea about CL approach, nor searched about the polysemous nature of English prepositions. As for the procedures followed, they include the following:

1) Illustrating to the participants $C L$ approach and its main principles;

2) Conducting a pre-test that contains images to be analyzed, sentences to be rephrased, and gaps to be filled;

3) Conducting a post-test which contains the same steps of the pre-test; and

4) Submitting a three-question questionnaire that reflects the participants' view about CL approach.

\subsection{Pre-test}

Result of the pre-test was (68) marks collected by the researcher. This score reflects the participants' progressive view about CL after they have just had a simple idea about the approach. It further reflects the participants' difficulty in comprehending and differentiating among the usages of at and other prepositions. The score further reveals that the participants cannot deeply analyzing the spatial sense or getting the spatial relations or figurative sense of the preposition in the sentences. Moreover, the resulted score reveals that the participants depended on their previous notion of the preposition and its uses. Besides, most of them failed to identify the spatial scene or find the entities in the sentences or pictures. They also committed vital mistakes in filling in the gaps with the appropriate preposition.

\subsection{Post-test}

Ten weeks of illustration were spent to explain about CL approach using the experiment of Tyler and Evans in (2003), conducting the tests, and doing the semantic analysis of the English preposition at. During this period of time, the participants watched videos that clearly explained CL approach, and showed its merits in comparison to other traditional accounts in analyzing prepositions. The participants worked in groups and rephrased sentences with the preposition at and defined their meanings. They also interpreted pictures and defined the spatial sense and relations found in each picture. When it was time for the test, they did the same tasks but individually.

Throughout the results of the post-test, the participants showed a remarkable improvement in analyzing images that have the preposition in question, and identified the spatial sense and relation created by this preposition. They achieved a notable awareness of the meaning and usages of $a t$. They were further able to grasp the surface meaning, 
and connect between the entities and their relations. They were also capable of eliciting the figurative sense derived from the spatial scenes.

The following table shows the difference between the pre-test and post-test marks of the participants. The marks of the participants are not mentioned here to save spaces. The results were analyzed using SPSS statistical editor.

Table 1. The difference between the pre-test and post-test

[DataSet0]

\begin{tabular}{llllcc}
\hline \multicolumn{5}{c}{ Paired Samples Statistics } \\
\hline \multirow{2}{*}{ Pair 1 } & Mean & $\mathrm{N}$ & Std. Deviation & Std. Error Mean \\
& Pre-test & 11.23 & 68 & 2.512 & .292 \\
& Post-test & 15.81 & 68 & 1.676 & .201 \\
\hline \multicolumn{5}{c}{ Paired Samples Correlations } \\
\hline Pair 1 & Pre-test \& post-test & 68 & .214 & Sig. \\
\hline
\end{tabular}

Note. If the difference between both tests is less than $(0.05)$, then, the study is invalid.

If the difference between both tests is more than $(0.05)$, then, the study is valid.

Table 1 shows the number of the participants which is 68 , and their average in the pre-test, which is 11.23 , and the post-test, which is 15.81 . The participants showed a progress of 4.58 marks. Since the difference between the two means of both tests showed a progress that was more that $(0.05)$, then, this study is valid. The results are in agreement with the research of Evans and Tyler (2003). This means that CL approach can make a remarkable positive change within the participants' comprehension of English prepositions.

\subsection{Questionnaire}

The questionnaire is set to test the participants' acceptance to the new theory in analyzing prepositions and their meanings. Figure 5 below shows the participants attitudes clearly.

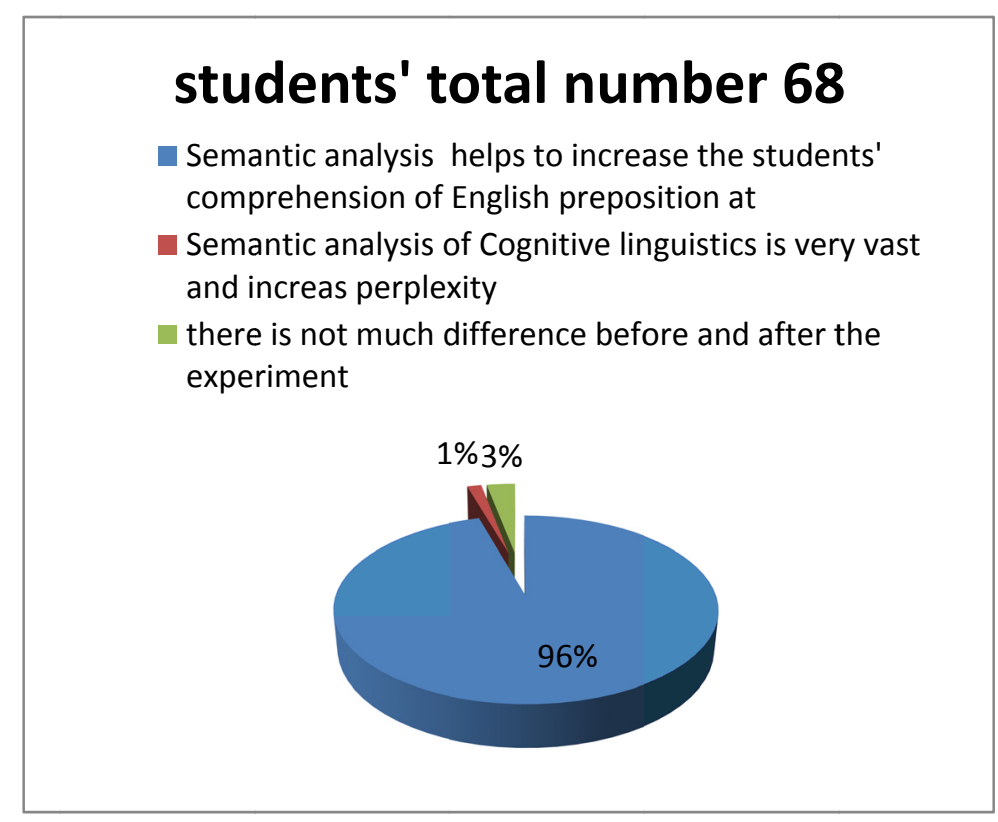

Figure 5. The questionnaire's results

The questionnaire clearly shows that $96 \%$ of the participants; that is, 65 out of 68 of the total number of the participants think that the cognitive semantic analysis is helpful. Moreover, $3 \%$, which represents 2 participants only find no difference after the experiment. In addition, $1 \%$; that is, 1 participant only has difficulty sitting for the experiment. 


\section{Results and Findings}

This experiment changes the participants' view when dealing with the English preposition at. It consolidates their information and enables them to comprehend the meaning of English preposition in different ways. It can expand the students' comprehension and interpretation to other English prepositions. Participants can use the schema diagram to draw figures for prepositions and identify the entities, spatial, and non-spatial relations. That is; generally speaking the cognitive linguistic models and/or theories enhance the conceptual way of thinking. In this regard, Al-Bahrani and Al-Robuye, (2016) further add that the cognitive linguistic theory of Matrix Domain by Langaker helps classify the different senses of the preposition at and keep the diagram set by them in the participants' mind when choosing the right sense.

Results of the test and the questionnaire have further proven the effectiveness of CL approach. Its new trends in explaining the conveyed meaning is unique and convincing. CL approach's views might not be ignored or neglected in acquiring a second language because it offers a better account when dealing with prepositions than that of the traditional ways. Moreover cognitive linguistic theory reflects the individual or subjective conceptualization of senses. By this, one can know about the way participants think and help them adjust in accordance with that of acquired language.

\section{Conclusion}

The use of CL approach in analyzing the meaning of the English preposition at is more effective and evident. Thus, using CL approach to increase the participants' awareness in comprehending some aspects of English prepositions is a priority. Specialists in applied linguistics and linguistic theories should have given the chance to play a bigger role in adopting the insights of such fields in facilitating the educational and linguistic problems encountered by the participants when acquiring English as a second language. Finally, this semantic analysis of prepositions promises a great utility in L2 classrooms.

\section{References}

Al-Baharani, R., \& Al-Robuye, M. R. (2016). A Cognitive Semantic Analysis of the Preposition At. Baghdad University.

American Association of Applied Linguistics. (2018, June 2). AAAL. Retrieved from https://www.aaal.org/page/DefAPLNG.

Bores, F. (1996). Spatial prepositions and metaphores: a cognitive semantic journy along the up-down and thefront-back dimensions. Language in Performance, 12.

Bores, F., \& Demecheleer, M. (1998). A cognitive semantic approach to teaching prepositions. ELT Journal, 52(3). https://doi.org/10.1093/elt/52.3.197

Brala, M. (2008). Understanding the English preposition 'at'. Semantics and translation from a cognitive perspective. University of Rijeka, Croatia

Casasanto, D., \& Boroditsky, L. (2008). Time in the Mind: Using space to think about time. Cognition (106, pp. 579-593). https://doi.org/10.1016/j.cognition.2007.03.004

Celce-Murica, M., \& Larsen-Freeman, D. (1999). The Grammar Book: An ESL/ EFL Teachers' Course. Rowely, Mass: New bury Hose.

Cienki, A. J. (1989). Spatial Cognition and the Semantics of Prepositions in English, Polish and Russian. Munchen: Verlag Otto Sanger. https://doi.org/10.3726/b12805

Evans, V. (2012). Cogniotive Linguistics. Brighton: University of Sussex.

Fernando, I. (1998). A Cognitive Semantic Analysis of the Lexical Units At, On, And In in English. Jaume University.

Geeraerts. D., \& Cuyckens. H. (2010). Introducing Cognitive Linguistics. Oxford: Oxford Handbook. https://doi.org/10.1093/oxfordhb/9780199738632.013.0001

Hawkins, B. W. (1984). The Semantics of English Prepositions. University of California. San Diego, PHD. Dissertation.

Mandreali, F., Martoglia, R., \& Ronchetti, E. (2005). Improving Semantic Awareness of knowledge-based Application through Structural Disambiguation. Di Modena University, Modena Italy.

Mueller, C. (2016). A Semantic Account of The English Preposition FOR Based on a Cognitive Linguistics Framwork. The Bulletin of the Faculty of Humanities, 53, 1-24. 
Rhee, S. (2004). Semantic structure of English preposition: an analysis from a gramaticalization perspective. Language Research, 40(2), 397-427.

Rice, A. S. (1992). Polysemy and Lexical Representation: The Case of Three English Prepositions. Edmonton, Canda: University of Alberta.

Saed, A. H., \& Yassin, B. (2017). Jordanian Undergraduate Students' Use of English Prepositional Verbs: Analytical Study. Canadian Social Science, 13(4), 68-75.

Tyler, A., \& Evans, V. ( 2004). Applying Cognitive Linguistics to Pedagogical Grammar: The case of Over. In M. Achard \& S. Niemeier (Eds.), Cognitive Linguistics, Second Language Aquisition, and Foreign language Teaching (pp. 257-280). Berlin: Mont de Gruyter. https://doi.org/10.1515/9783110199857.257

Tyler, A., \& Evans, V. (2003). The Semantics of English Prepositions: spatial scenes, embodied meaning, and cognition. Cambridge: UK Cambridge University Press. https://doi.org/10.1017/CBO9780511486517

Tyler, A., Mueller, C. M., \& Ho, V. (2011). Applying Cognitive Linguistics to Learning the English Prepositions To, For, and At: an experimental investigation. Vigo International Journal of Applied Linguistics, (8), 122-140.

Vasardani, M., Striling, L., \& Winter, S. (2017). The preposition at from a spatial language, cognition, and information systems perspective. Semantics and Pragmatics, 10(3). https://doi.org/10.3765/sp.10.3

Winter, S., \& Christian, F. (2012). Approaching the notion of place by contrast. Journal of Spatial Information Science, (5), 31-50. https://doi.org/10.5311/JOSIS.2012.5.90

\section{Copyrights}

Copyright for this article is retained by the author, with first publication rights granted to the journal.

This is an open-access article distributed under the terms and conditions of the Creative Commons Attribution license (http://creativecommons.org/licenses/by/4.0/). 